\title{
Inclusive Planning: African Policy Inventory and South African Mobility Case Study on the Exclusion of Persons with Disabilities and Other Vulnerable Groups
}

Marianne J.W.A. Vanderschuren ( $\nabla$ marianne.vanderschuren@uct.ac.za )

University of Cape Town https://orcid.org/0000-0002-1691-0872

Obiora Nnene

University of Cape Town

\section{Research}

Keywords: Africa, disability, mobility challenges, transport, policy, planning

Posted Date: December 21st, 2020

DOl: https://doi.org/10.21203/rs.3.rs-131860/v1

License: (a) (1) This work is licensed under a Creative Commons Attribution 4.0 International License.

Read Full License 


\section{Abstract}

\section{Background}

Almost half of the African population is under the age of 18 years, while females make up just over half of the overall population. Estimates of the number of persons living with disabilities, on the African continent, range between 60-300 million individuals. Children, the elderly, females and people with disabilities all require amendments to traditional transport planning.

Method

This paper investigates the availability of transport policies and guidelines in 29 different African countries, focussing on the inclusion of persons with disabilities, women and children. A desktop study was conducted, followed by the analysis of secondary data in the case study area, South Africa, demonstrating that the lack of adequate policies, guidelines and appropriate implementation leads to a lack of accessibility, opportunities and social isolation.

Results

The data analysed revealed that Ghana and Kenya, have the most inclusive policy and legislative framework, while Tanzania has the most inclusive transport related framework. The private sector, NGOs, and NPOs are most active in the inclusion of people living with disabilities in Ghana, Ethiopia, Uganda, Tanzania and South Africa.

In South Africa (STATSSA, 2013), over 2.2 million people (4.5\% of the population) did not travel at all in the seven days before the interview, as their disability or age prohibits them to do so, or due to a lack of appropriate services. When comparing the trip rates per week, people with disabilities travel significantly less than their abled counterparts, between $65.8 \%$ and $27.2 \%$ less.

\section{Conclusions}

The study concludes that people with disability live less integrated, more isolated lives, due to the lack of accommodating infrastructure and services, in addition to the lack of binding policies, legislation, standards and guidelines. The results underpin the need for Disability Inclusive Planning in the African context and provides recommendations that mitigate the isolation challenges faced by people with disabilities.

\section{Introduction}

\section{Transport Research on Vulnerable User Groups}

Research challenges of transport planners demonstrate shifting priorities over time, relating to strategic priorities. In the 1970s the focus was enhancing road capacity where drivers were predominantly male, 
middle class workers using private motor vehicles (Nash, 1976). Four decades later, the focus shifted to recognising the needs of vulnerable transport user groups, highlighted the need focus research attention on identifying gender issues in transport planning (Allen and Vanderschuren. 2016). According to the authors, a further key area of research for the future is transport planning for persons with disabilities.

Allen and Vanderschuren (2016) identified the Transport Research International Documentation (TRID) database as the most inclusive data source. The TRID database includes more than 1090000 records, of which 156000 records are linked to full text documents.

Analysing publications in the TRID database, over the past two decades, across all modes of transport, revealed a limited number of research publications focussing on people with disabilities. Table 1 provides a summary of the number of publications found.

Table 1

Number of Research Publications in TRID Database (2000-2020)

\begin{tabular}{|lllllll|}
\hline Type of Impairment & $\begin{array}{l}\text { Disability } \\
\text { (general) }\end{array}$ & Inclusivity & Mobility & Intellectual & Vision & Epilepsy \\
\hline Number of publications & 83 & 5 & 12 & 12 & 1 & 1 \\
\hline
\end{tabular}

Table 1 Number of Research Publications in TRID Database (2000-2020)

Over the two decades analysed, research reports on transport related challenges, for people with disabilities, were limited. During the same period, 25 research documents were listed on the elderly and 13 documents on child mobility challenges and transport. A mere 27 records were deemed suitable for the gender study focussing on the security of females and girls, while using public transport/transit (Allen and Vanderschuren 2016).

Based on the analysis of the number of transport related research publications, it can be concluded that, persons with disabilities, the elderly, children, and gender-based studies are under-represented in mainstream research documents.

\section{Vulnerable User Groups in Africa}

Africa is a young continent. With a median age of 19.7 years (i.e. $50 \%$ of the population is younger than 19.7 years), the region ranks number two among regions of the world (roughly equivalent to "continents"), ordered by population (https://www.worldometers.info/world-population/africa-population/). In SubSaharan Africa, the gender split is equal. In 2019 , females made up $50.102 \%$ of the population (https://data. worldbank.org/indicator/ SP.POP.TOTL.FE.ZS?locations = ZG).

The Global Burden of Disease Report, based on country reports of mortality and loss of health, because of disease and injury, estimated the global prevalence of disability to be $15 \%$, with higher prevalence rates estimated for low-income countries (Global Burden of Disease Report 2010, 
https://www.who.int/pmnch/media/news/2012/who_burdenofdisease/en/). Some $80 \%$ of persons with disabilities live in developing countries, while an estimated 60-80 million of them are living in Africa (www.disabled-world.com). A World Health Organization source maintains that about $40 \%$ of Africa's population consists of people with disabilities, including $10 \%-15 \%$ of school-age children. This percentage would translate into about 300 million people with disabilities in Africa. Disability is caused by many factors, including malnutrition and disease, environmental hazards, traffic crashes and industrial accidents, as well as civil conflict and war. The number of people with disabilities in Africa, continues to increase (https://www.ascleiden.nl/content/webdossiers /disability-africa\#).

The apparent under-reporting of disability in low-income countries has been attributed, in part, to the stigma associated with disability and reporting methodologies (Baskind and Birbeck, 2005; Green, 2003; RAVIM and Handicap International Mozambique, 2010; Sorsdahl et al., 2012; Schneider, 2009). The UN Workshop on Disability (Kampala, 2001) found that, in many African societies, there are socio-cultural pressures to under-report disability. Respondents are reluctant to admit the presence of persons with disabilities in the household and interviewers tend not to ask about disability unless a person with a very severe kind of disability is seen during the interview.

This lower reported prevalence rate is evident in South Africa, where the National Census estimated the prevalence of disability to be $7.5 \%$ of the population in 2011 (STATSSA, 2012). The highest prevalence of disability has been reported among those with lower income, particularly those who had no schooling (10\%) compared to those who had post-secondary education (3\%) (STATSSA, 2012). Black Africans in South Africa who, generally, reside in under-resourced communities, were still found to have the highest rate of disability $(7.8 \%)$ in the 2011 census (STATSSA, 2012).

In the UN Disability Statistics (https://unstats.un.org/unsd/demographic-social/sconcerns/ disability/ statistics/\#/countries), only 11 African countries report on disability levels. Of these, Senegal and South Africa do not provide a differentiation into types of disability. For all other available country data, the information is included in Fig. 1.

Most data included was from 2012-2014. The exception was Tanzania, with data from 2017. Underreporting, as identified by various sources, is also apparent in the UN disability statistics. The countries that do report data, on average, report that $4.9 \%$ of their population live with disabilities. Exceptions are Tanzania and Zimbabwe, both reporting $9.1 \%$ of the population living with disabilities. Although these percentages are significantly higher than data for other African countries, they are still far below the $15 \%$ indicated by the Global Burden of Disease Report (GBD, 2010).

Furthermore, disability reporting categories are not standardised amongst African countries. Upper (4 countries) and lower (3 countries) limb-based disabilities are only reported by a limited number of countries. Cameroon and Guinea report zero paralysis cases, while Tanzania does not report any cases of speech impairment. These statistics, in reality, are highly unlikely. 
Zimbabwe reports a significantly higher number of cases of vision impairments (4.2\%), paralysis (3.5\%), as well as the highest percentage of people with a hearing impairment (1.75\%). Rwanda reports the highest level of paralysis cases $(2.35 \%)$, while Tanzania reports the highest number of people with mental/learning disabilities (2.05\%).

Figure 1. Types of Disability in Selected African Countries

Research by Human Rights Watch (https://www.hrw.org/world-report/2018) over the last five years, in the Central African Republic, Cameroon and South Sudan, amongst others, shows that, in situations of armed conflict, people with disabilities have faced violent attacks, forced displacement, and ongoing neglect in the humanitarian response to civilians caught up in the fighting. In some cases, people with disabilities were abandoned in their homes or in deserted villages for days or weeks, with little access to food or water, and many died, due to their inability to flee attacks. People with disabilities who reached sites for international displaced people, or refugees, often faced unparalleled difficulties accessing food, sanitation and medical assistance (https://www.hrw.org/world-report/2018).

This paper investigates the inclusivity, or lack thereof, of transport planning for vulnerable population groups across a range of African countries, based on a literature review. Using South Africa as a case study, the paper then demonstrates the isolating effect that a lack of inclusive transport planning has on these vulnerable population groups, based on household survey data.

\section{Methodology}

This study consists of two distinct parts, a desktop study of available transport policy and planning documents in African countries, and an analysis of secondary household data.

The desktop study was used to identify transport policy and planning documents and assess the existence of gender, age and disability sensitive planning in Africa. The data utilised was collected online, during the months of June/July 2020 , by three researchers who were recruited for the purpose.

In total, 29 sub-Saharan African countries were surveyed: 11 Francophone and 18 Anglophone ones. The countries were from East, West, Central, Southern and Northern Africa. The countries surveyed include Algeria, Angola, Benin, Botswana, Burkina Faso, Burundi, Cameroon, Congo, Cote d'Ivoire, Democratic Republic of Madagascar, eSwathini, Eritrea, Ethiopia, Gabon, Gambia, Ghana, Guinea, Kenya, Lesotho, Liberia, Malawi, Mauritius, Namibia, Nigeria, Rwanda, Senegal, Sierra Leone, South Africa, Tanzania, Uganda, Zambia and Zimbabwe.

The data for each country was collated in two distinct segments. The first one relates to legislative and institutional support for Persons With Disabilities (PWDs) within the countries. Here documents, such as the country's constitution and other policy documents that address the living conditions of PWDs, with the aim of improving overall access to the various sectors of the economy, are collected and reviewed. The second segment collated data indicating the availability of transport sector-specific provisions for 
particular types of disabilities within each country. The checklist used to guide the data collection for these segments are as follows:

- available policies for PWDs,

- visual impairment,

- hearing impairment,

- mobility aid,

- women,

- children,

- the elderly, and

- total data collected.

The second part of the study uses existing, secondary data for South Africa, to assess the level of isolation for the vulnerable population groups identified, i.e. children, the elderly women and PWDs.

The South African National Household Travel Survey (SANHTS) is used to analyse (STATSSA, 2013):

- Female mobility and gender specific transport challenges,

- Child mobility and youth related transport challenges, and

- Mobility levels for PWDs and the elderly.

The next section (Sect. 3) unpacks current disability sensitive planning trends within the Sub-Saharan African (SSA) transport sector, and how these have impacted PWDs, as the UN reports on the number of people living with disability in SSA countries, combined with itemised capacity building and knowledge transfer as some of the strategic needs of the transport sector, in their local context. This analysis is followed by Sect. 4, which unpacks mobility challenges for vulnerable populations.

\section{African Policy And Planning Comparison}

The result of analysing the documents and data is presented in the form of the total counts of data for each country and addresses the indicators stated in the previous section. The results are also presented in the three earlier mentioned categories i.e. policy, legislative and institutional framework, transportation policy and private sector participation.

\section{Legislative and Institutional Support}

The results of the analysis of policy and legislative documents, as well as the institutional framework, is presented in Fig. 2. Maps are provided of the surveyed countries, with the colour intensity representing the amount of data that was obtained during the data collection stage. The raw values have been normalised into a scale between zero and ten, to minimise the variation therein. In terms of the availability of policies 
for PWDs, Ghana and the Democratic Republic of the Congo (DRC) have the highest number of sources accessible online, while Liberia has the least.

The maps also reveal that, at a national or strategic level, the countries surveyed recognise the need to put in place the necessary legal and legislative frameworks that are aimed at eliminating barriers faced by PWDs and other vulnerable groups in the society. This is mainly in the form of laws and policies by various agencies of government in the countries. However, it should be noted that the existence of these laws does not, necessarily, guarantee that they are implemented in practice, or enforced by institutional processes and the police. Discussions on the implementation and policing of these laws is beyond the scope of this report.

The DRC and Ghana have the most comprehensive policy framework, followed by Zambia, Kenya, Malawi, Senegal and Madagascar (in that order). Policy and legislation in Ghana are most inclusive for the visually and hearing impaired, followed by Kenya and Malawi and, to a lesser extent, Gambia. Mobility impairment is also included in the Ghanaian policy and legislation framework, followed by Kenya and Malawi (in that order). Ghana's policy and legislation framework includes the needs of children, while Ethiopia, Malawi, Gabon and Uganda are front runners regarding the consideration of the elderly.

South Africa and Tanzania have the most inclusive policy, legislation and institutional framework for women. Despite gender inclusive planning, South African practice still shows a lack of gender equality. Unacceptable levels of gender-based violence can be identified from the \#JustNo movement. Salary differences in South Africa between males and females also prove that a good policy and legal framework does not always translate to best practices on the ground. South Africa has experienced a decline of the gender wage gap at the mean from about $40 \%$ in 1993 to about $16 \%$ in 2014. However, the gap declined only until 2007 and was stagnant thereafter, oscillating at 16\% (UNU-WIDER, 2019). The gender wage gap, independent from race, in the South African labour market also exhibits a 'sticky floor' effect - a pattern that keeps a certain group at the bottom of the job scale, with the bottom decile of earners having the highest proportion of female workers.

Figure 2 Available Policy Frameworks, Disability Types and Vulnerable Groups

The gender wage gap is also highest at the top 10th percentile, which reflects the fact that South African women rarely occupy the highest-paying positions in the economy. (UNU-WIDER, 2019), which reinforces the notion that policies and legislation alone do not guarantee equitable practices. Ghana and, to a lesser extent, Kenya, have the most inclusive general policy and legislation framework.

\section{Transport Policies}

The results presented in Fig. 3 are normalised, in an identical manner to the previous section. The specific focus in this section is on online availability of transport related plans, policies and strategies, and whether they make provisions for PWDs and other vulnerable groups. 
Figure 3 Available Transport Policy Frameworks, Disability Types and Vulnerable Groups

South Africa, Cameroon, Gabon and Ivory coast are the countries with the highest number of accessible transportation policies. South Africa also has the highest number of transport related documents that include vision impairment; other countries have $66 \%$ or less of the documents. Nigeria and Tanzania are the front runners regarding hearing impairment related transport policies. Other countries have only half the documentation of these two countries, or less.

South Africa's transport policy documents are clearly superior regarding mobility aid requirements, with others, i.e. Tanzania and Malawi, having three quarters or less. Tanzania's and Malawi's transport policy documents generally profile the needs of children and women more, compared to the other African countries included in this desktop study. Malawi also tops the inclusion of the elderly, with other countries scoring $50 \%$ or less on the inclusion of this age group.

Overall, Tanzania's and Malawi's transport policies are the most inclusive of the African countries.

\section{The Isolation Of Vulnerable Groups In South Africa}

\section{Women}

International literature reveals that women make more trips than men (for example, McGuckin and Murakami, 1995); they undertake care trips more often (care trips include food shopping, taking children to school or sick family members to the doctor) and they are more likely to show trip changing behaviour (Peters, 2001; Allen and Vanderschuren, 2016).

In South Africa, the trip frequency between males and females does not differ substantially. Furthermore, the mode of transport used for trips is also very similar. More males $(16.9 \%)$ than females $(11.8 \%)$ are car drivers, while more females $(13.2 \%)$ than males $(10.9 \%)$ are car passengers. Slightly more females $(24.5 \%$ overall) than males (23.5\% overall) use public transport. Females favour bus and MiniBus Taxi (MBT) over the train (Vanderschuren et al, 2019). Furthermore, more women (31\% versus $27 \%$ ) travel to work, while males make more business trips ( $25 \%$ versus only $4 \%$ ). Women also make more ( $10 \%$ versus $6 \%$ ) educational trips (Vanderschuren et al., 2019).

The SANHTS (STASSA, 2013) reveals that security is a major concern for travellers. Between $20 \%$ and $56.5 \%$ of household heads consider (parts of) the public transport journey risky. Trains are considered the least safe, hence, the finding that women prefer other modes of transport. A questionnaire amongst train passengers in Cape Town revealed that, while males only experience pickpocketing (83\%) and muggings (17\%), females are exposed to pickpocketing (37\%) and muggings (47\%), as well as verbal $(10 \%)$ and sexual (6\%) harassment (Vanderschuren et al., 2019).

\section{Children}


In 2003 , the SANHTS showed that $90.6 \%$ of the 7.5 million learners and students in South Africa, living in rural and peri-urban areas, walked to schools and educational centres. In contrast, the 2013 version of the SANHTS survey (STASSA, 2013) revealed the following trends:

- Approximately $63 \%$ of learners walked the entire distance to educational institutions, while those attending tertiary institutions tended to use taxis more than any other mode of transport. This shows a decrease of $27.6 \%$ in the number of children who walked in 2003 , as seen previously. This trend is because of an increase in the percentage of passengers who are learners.

- The percentage of learners walking all the way to school varies from $43 \%$ in Gauteng to $79 \%$ in Limpopo; the more rural a province, the greater the likelihood of learners walking all the way.

- In 2001, the National Department of Transport (DoT) initiated the Shova Kalula (Ride Easy) Programme to provide bicycles to school-going children to enable easier travel to schools. The survey revealed that bicycle use in the country has slightly increased by about $1.5 \%$ since 2003 , suggesting that the Shova Kalula Programme has, so far, had a negligible impact on most children who walk to school.

South Africa is one of the highest contributors to Africa's road fatality figures. For the general population, the country has the second highest fatality rate in Africa, at 31.7 fatalities per 100000 population (Peden et al., 2013); and the fatality rate for children, is double that of the global fatality rate (Matzopoulos et al., 2008). For children aged $0-19$ years road crashes account for $20 \%$ of all passenger and pedestrian deaths (Janmohammed and Ribbens, 2018).

\section{Persons with Disabilities}

According to the SANHTS (STATSSA, 2013) South Africa has 4.15 million adults that have some or severe vision impairment while travelling (see Fig. 4). Furthermore, there are 1.69 million people that receive an old age or disability grant (other than for the listed disability types).

Figure 4. South African Adult Population (18 and older) with Various Disability Types

Another 0.5 million people have a hearing impairment, while 0.70 million people use a walking frame or stick to aid their mobility and 0.12 million people are wheelchair users (see Fig. 4). There are also 319000 South African inhabitants that have concentration issues. Independent mobility can be challenging for this population group.

When analysing the weekly trip rates of people with disabilities, compared to the average adult South African, a high level of risk of isolation is clearly displayed. As can be seen in Fig. 5, persons with vision impairment make $39.2 \%$ fewer trips than their abled counterparts, while persons with a hearing impairment travel $47.2 \%$ less. People with mobility impairments, either using a stick, walking frame or wheelchair, travel $65.8 \%$ less than able-bodied people. The analysis also revealed that concentration impairment (-52.9\%), self-care challenges (-27.2\%) and communication impairment (-35.6\%), reduce mobility and contribute to isolation. 
Figure 5 Reduction in Trip Making for South African Adults (18 and older) with a Disability

\section{Conclusions}

A people-centric, inclusive transport system is required to move towards safe, secure and liveable cities. The paradigm shift focussing on people rather than vehicle needs will encourage walking and cycling, and protect vulnerable road users, such as children, the elderly, women and people with disabilities. More walking and cycling will, in turn, reduce negative environmental impacts. People-centric, inclusive transport systems require transport policies, legislation, standards and guidelines that pay special attention to the vulnerable groups listed. Furthermore, transport facilities and services need to reflect the planning requirements.

Africa still has a long way to go regarding the development and implementation of people-centric, inclusive transport planning. Many countries lack appropriate planning documents, leading to a lack of care for vulnerable road users in practice. Ghana and, to a lesser extent, Kenya, have the most inclusive general policy and legislative framework, while Tanzania has the most inclusive transport related framework.

South Africa needs to improve its transport policies, legislation, standards and guidelines to include more care for vulnerable groups. Based on an analysis of the South African National Household Travel survey data (2013), focussing on the inclusivity of vulnerable road users, it can be concluded that the lack of people-centric, inclusive transport planning and implementation, has led to increased road safety and personal security risk, as well as an increasing risk of isolation.

While South African women experience a high security risk when travelling, and our children are twice as likely to become a road fatality, compared to the global average, PWDs are likely to be at risk of isolation, due to the lack of appropriate infrastructure and service provision. When comparing the trip rates per week, PWDs travel significantly less than their abled counterparts. Their trip rates are between $27 \%$ and $66 \%$ less than their abled bodied, adult counterparts.

Currently, across Africa, the lack of infrastructure and services to accommodate vulnerable road users, that is evident as a result of a lack of binding and enforceable policies, legislation, standards and guidelines, serves to jeopardise vulnerable individuals' safety, security, freedom and dignity.

\section{Declarations}

\section{Ethics Approval and Consent to Participate}

Ethics approval for this study was received from the University of Cape Town. Participant consent was not required as only secondary data was used.

\section{Consent for Publication}


The research team received written consent from the funder regarding publication of this work.

\section{Availability of Data and Materials}

Data sources used during the desk top study are freely available online. The South African National Household Travel Survey can be sources from the South Africa Bureau of Statistics.

\section{Competing Interests}

There are no competing interests related to this work.

\section{Funding}

This research was sponsored by the UKAid's Research for Community Access Partnership (ReCAP) programme. The programme responds to the identified critical shortage of well-rounded leaders in SSA's transportation sector. One of the identified shortfalls is the understanding of the need for inclusive planning that caters for all modes and population groups, independent of their (mental or physical) capabilities or other vulnerabilities. The contents in this paper will serve as input into the Centre of SubSaharan Africa Transport Leadership's (CSSTL) flagship capacity building programme known as the Masters in Transport Leadership (MTL) and, hopefully, beyond.

\section{Authors Contributions}

The authors have made an equal contribution to this paper.

\section{Acknowledgements}

The authors would like to thank Mr Nkululeko Leta, Prof Mark Zuidgeest, Mr Kieran Kelly, Mr Stephen Jones and Prof Charles Adams for their ongoing guidance, Mr Stephane Masamba and Ms Lerato Molefe for their assistance in the data collection and Ms Alison Gwynne-Evans and Ms Cheryl Wright for her editing advice.

\section{References}

Allen H. and M. Vanderschuren, 2016. Safe and Sound, International Research on Women's Personal Safety on Public Transport. The FIA Foundation, Paris, France.

Baskind R. and G. Birbeck, 2005. Epilepsy Care in Zambia: A Study of Traditional Healers, Epilepsia, 46(7), 1121-1126.

Green S.E, 2003. "'What do you mean 'what's wrong with her?": Stigma and the lives of families of children with disabilities', Social Science \& Medicine 57(8), 1361 10.1016/S0277-9536(02)00511-7.

Janmohammed A. and H. Ribbens, 2018. Prevention of Road Injuries Impacting Children in South Africa, Review of Child Road Injury Prevention Measures Literature, by ChildSafe and the University of Cape 
Town for UNICEF.

Matzopoulos, R., N. Du Toit, S. Dawad, and S. Van As, 2008. Assessing the prevention response to child road traffic injuries. Crime, Violence and Injury Prevention in South Africa: data to action. Tygerberg: Medical Research Council-University of South Africa Crime, Violence and Injury Lead Programme. 1025.

McGuckin, N. and E. Murakami, 1995. Examining trip-chaining behaviour: a comparison of travel by men and women, Federal Highway Administration. Washington, DC, FHWA.

Nash C.A., 1976. Urban Passenger Transport. In: Public versus Private Transport. Macmillan Studies in Economics. Palgrave, London. https://doi.org/10.1007/978-1-349-15629-0_5.

Peden, M., Kobusingye, O. and Monono, M.E. 2013. Africa's roads - The deadliest in the world. South African Medical Journal. 103(4):228-229. DOI: 10.7196/SAMJ.6866.

Peters, D., 2001. Gender and transport in less developed countries: A background paper in preparation for CSD-9. In London, Paper Commissioned by UNED Forum.

RAVIM \& Handicap International Mozambique, 2010. People with disabilities in the suburban areas of Maputo and Matola,Handicap International Mozambique, Maputo.

Schneider M., 2009. 'The difference a word makes: Responding to questions on "disability" and "difficulty" in South Africa', Disability and Rehabilitation 31(1), 42-50. 10.1080/09638280802280338.

Sorsdahl K.R., R. Kakuma, Z. Wilson and D.J. Stein, 2012. 'The internalized stigma experienced by members of a mental health advocacy group in South Africa', International Journal of Social Psychiatry 58(1), 55-61. 10.1177/0020764010387058.

Statistics South Africa (STATSSA), 2012. Census 2011: Census in brief, Statistics South Africa, Pretoria.

Statistics South Africa (STATSSA), 2013. National Household Travel Survey (SANHTS), 2013 [dataset]. Version 1. Pretoria: Statistics South Africa [producer], available 2014. Cape Town: DataFirst [distributor], 2014. DOI: https://doi.org/10.25828/zs4k-hb60

UNU-WIDER, 2019. The gender wage gap in post-apartheid South Africa. Research Brief 2019/2. Helsinki: UNU-WIDER.

Vanderschuren, M.J., S.R. Phayane, and A.J. Gwynne-Evans, 2019. Perceptions of gender, mobility, and personal safety: South Africa moving forward. Transportation research record, 2673(11), pp.616-627.

Web-based resources

https://www.ascleiden.nl/content/webdossiers / disability-africa\# 
https://data.worldbank.org/indicator/SP.POP.TOTL.FE.ZS?locations=ZG

www.disabled-world.com

https://trid.trb.org/

https://unstats.un.org/unsd/demographic-social/sconcerns/ disability/ statistics/\#/countries

https://www.hrw.org/world-report/2018

https://www.who.int/pmnch/media/news/2012/who_burdenofdisease/en/

https://www.worldometers.info/world-population/africa-population/

\section{Figures}

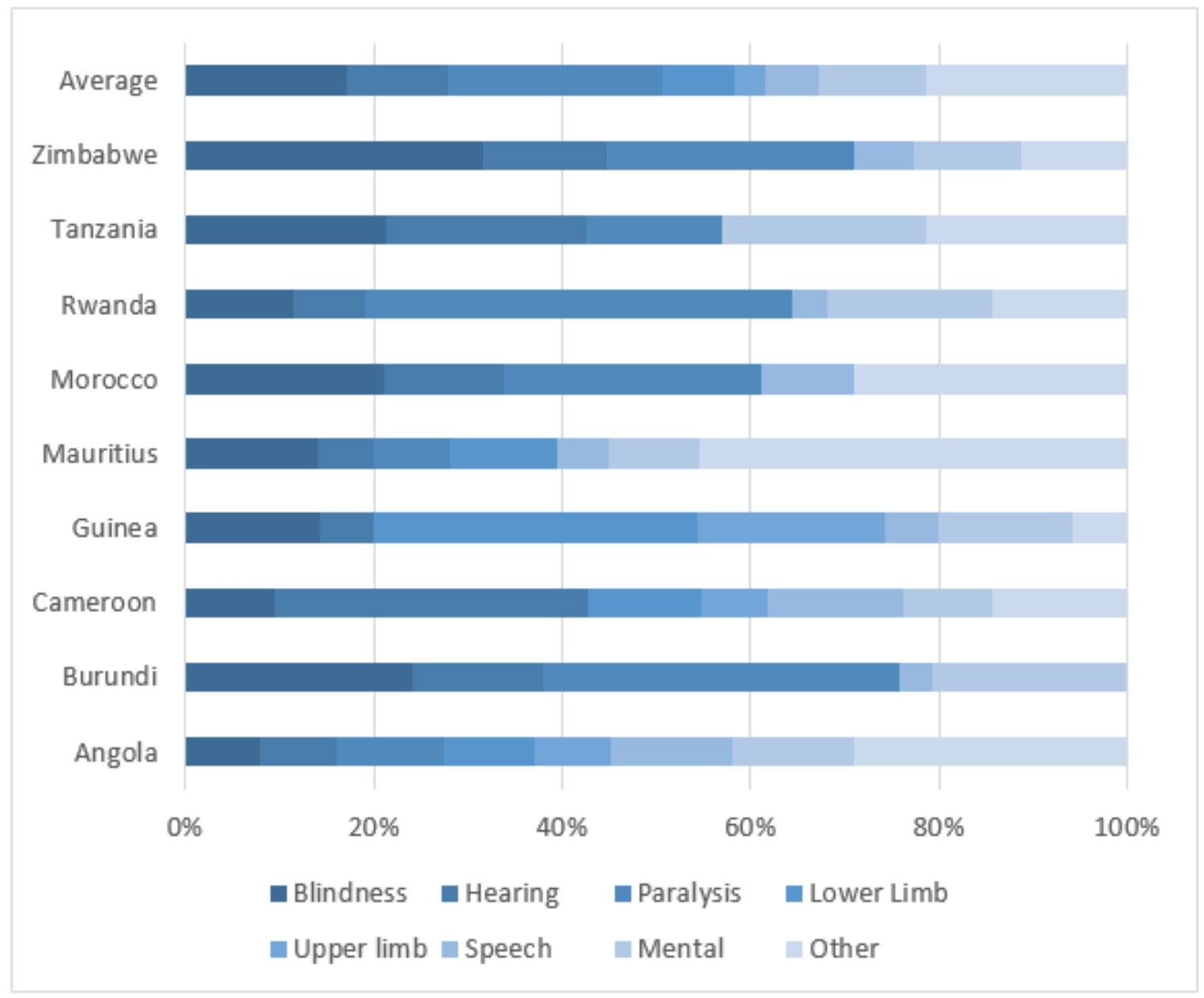

\section{Figure 1}

Types of Disability in Selected African Countries Source: UN Disability Statistics, accessed 30 August 2020 


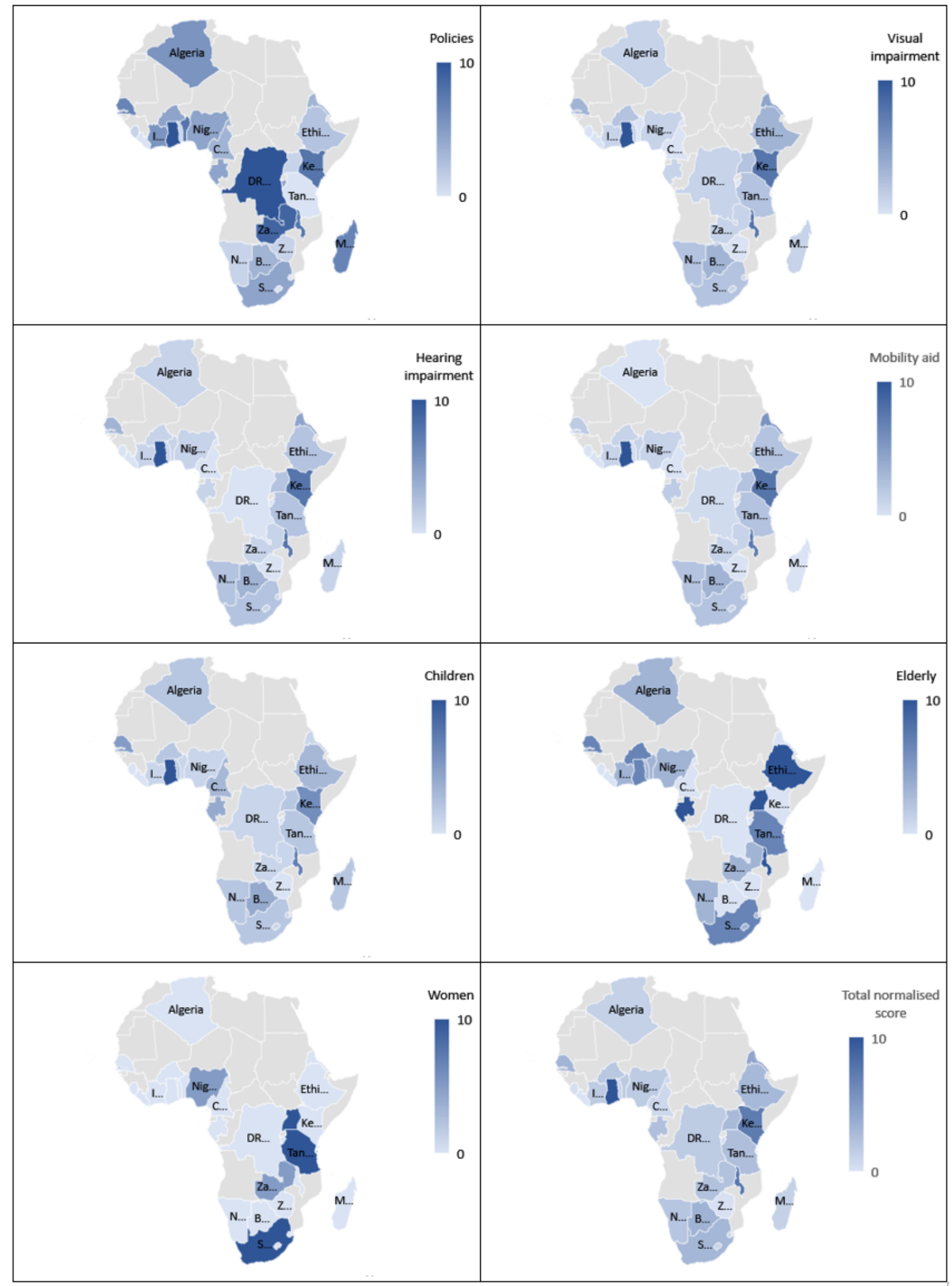

\section{Figure 2}

a - h - Available Policy Frameworks, Disability Types and Vulnerable Groups Powered by: GeoNames, TomTom, Wikipedia Note: The designations employed and the presentation of the material on this map do not imply the expression of any opinion whatsoever on the part of Research Square concerning the legal status of any country, territory, city or area or of its authorities, or concerning the delimitation of its frontiers or boundaries. This map has been provided by the authors. 


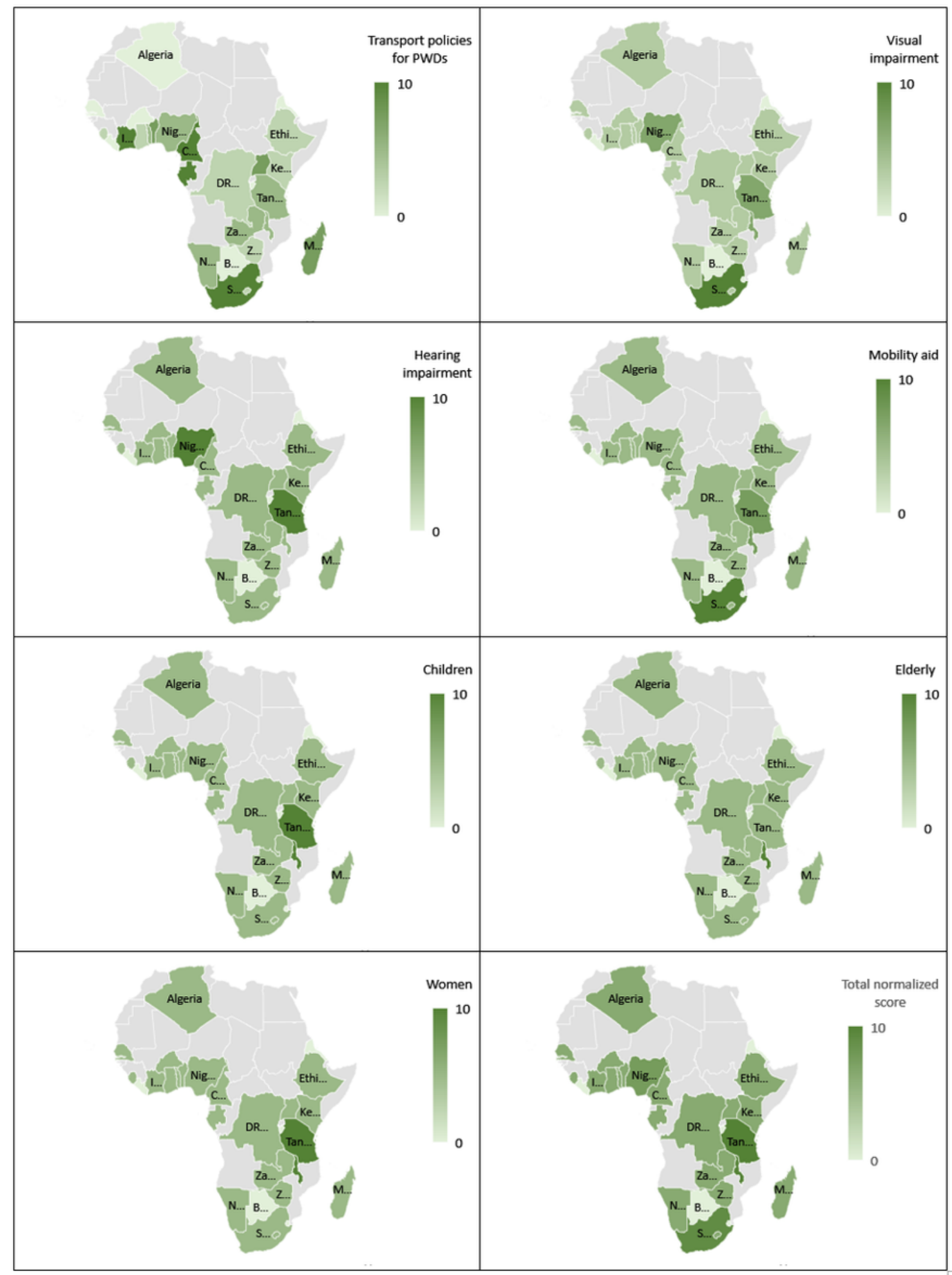

\section{Figure 3}

a - h - Transport Policy Frameworks, Disability Types and Vulnerable Groups Powered by: GeoNames, TomTom, Wikipedia Note: The designations employed and the presentation of the material on this map do not imply the expression of any opinion whatsoever on the part of Research Square concerning the legal status of any country, territory, city or area or of its authorities, or concerning the delimitation of its frontiers or boundaries. This map has been provided by the authors. 


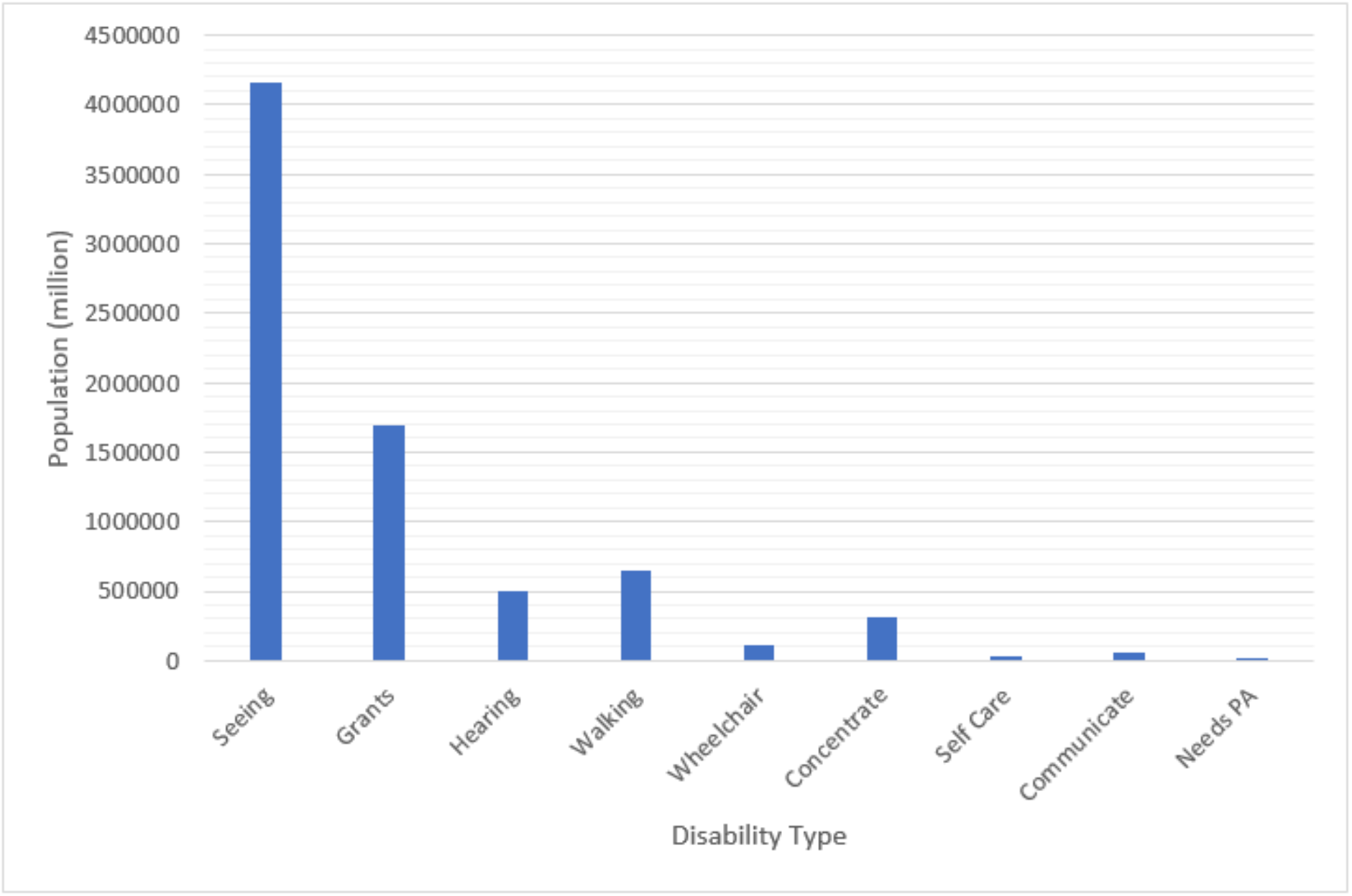

Figure 4

South African Adult Population (18 and older) with Various Disability Types Source: SANHTS; STATSSA, 2013 


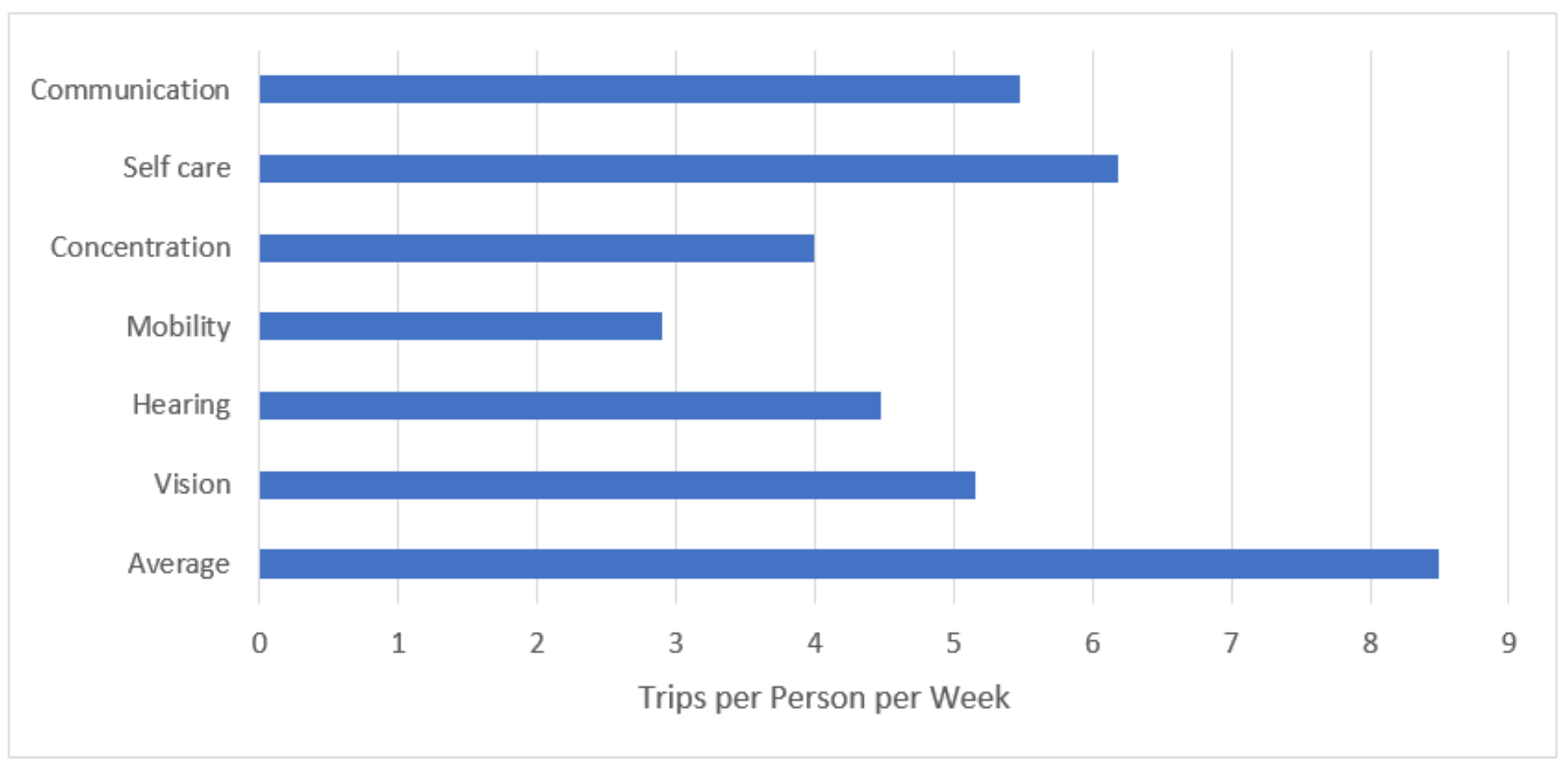

Figure 5

Reduction in Trip Making for South African Adults (18+) with a Disability Source: SANHTS; STASSA, 2013 